Research Paper

\title{
Clinical Practice in the Use of Adjuvant Chemotherapy for Patients with Colon Cancer in South Korea: a Multi- Center, Prospective, Observational Study
}

\author{
Jung Han Kim ${ }^{*}$, Moo Jun Baek2*, Byung-Kwon Ahn ${ }^{3}$, Dae Dong Kim, Ik Yong Kim5 , Jin Soo Kim6, \\ Byung-Noe Bae ${ }^{7}$, Bong-Gun Seo ${ }^{8}$, Sang Hun Jung ${ }^{9}$, Kwan Hee Hong ${ }^{10}$, Hungdai Kim ${ }^{11}$, Dong Guk Park ${ }^{12}$, Ji \\ Hye Lee ${ }^{13}$ \\ 1. Department of Internal Medicine, Kangnam Sacred-Heart Hospital, Hallym University College of Medicine, Seoul 150-950, Korea \\ 2. Department of Surgery, Soonchunhyang University College of Medicine, Cheonan, Korea \\ 3. Department of Surgery, Kosin University College of Medicine, Busan, Korea \\ 4. Department of Surgery, Daegu Catholic University Medical Center, Catholic University of Daegu School of Medicine, Daegu, Korea \\ 5. Department of Surgery, Wonju Severance Christian Hospital, Yonsei University Wonju College of Medicine, Wonju, Korea \\ 6. Department of Surgery, College of Medicine, Chungnam National University, Daejeon, Korea \\ 7. Department of Surgery, Sanggye Paik Hospital, Inje University College of Medicine, Seoul, Korea \\ 8. Department of Hemato-Oncology, Dongnam Institute of Radiological and Medical Sciences, Busan, Korea \\ 9. Department of Surgery, Yeungnam University College of Medicine, Daegu, Korea \\ 10. Department of Surgery, Inje University Sanggye Paik Hospital, Seoul, Korea \\ 11. Department of Surgery, Kangbuk Samsung Hospital, Sungkyunkwan University School of Medicine, Seoul, Korea \\ 12. Department of Surgery, Dankook University College of Medicine, Cheonan, Korea \\ 13. Medical department of sanofi-aventis Korea, Seoul, Korea \\ * Jung Han Kim and Moo Jun Baek equally contributed to this work.
}

$\triangle$ Corresponding author: Byung-Kwon Ahn, M.D. Department of Surgery, Kosin University College of Medicine, Busan 602-703, Korea. Phone: +82-51-990-6114, Fax: +82-51-990-3005, E-mail: gsabk@hotmail.com

(1) Ivyspring International Publisher. Reproduction is permitted for personal, noncommercial use, provided that the article is in whole, unmodified, and properly cited. See http://ivyspring.com/terms for terms and conditions.

Received: 2015.07.31; Accepted: 2015.11.01; Published: 2016.01.01

\begin{abstract}
Background: Adjuvant chemotherapy is a crucial part of treatment for patients with locally advanced colon cancer. This study was conducted to investigate the actual practice in the use of adjuvant chemotherapy for patients with high-risk stage II or stage III colon cancer in South Korea.

Methods: This was a 24-month open-label, prospective, observational study conducted at 12 centers across South Korea. Patients with high-risk stage II and stage III colon cancer receiving adjuvant chemotherapy after curative surgery were included, and data were collected at baseline, third, and sixth month.

Results: A total of 246 patients were included in the analyses. Of five available regimens (FOLFOX, CAPOX, 5-FU/LV, capecitabine, and UFT/LV), FOLFOX was most commonly used (82.5\%). Investigators indicated the "efficacy" as the major cause for selecting FOLFOX or CAPOX. For 5-FU/LV, capecitabine, or UFT/LV, the "safety" or "patient's characteristics (age, comorbidity, and stage)" was one of the most important selecting factors. Patients receiving 5-FU/LV, capecitabine, or UFT/LV had older age, worse PS and lower disease stage (stage II) than patients receiving FOLFOX or CAPOX. Hematologic toxicities were the most common cause of dose adjustment and treatment delay.

Conclusions: In South Korea, FOLFOX was the most commonly used regimen for adjuvant chemotherapy and its efficacy was the main cause for selecting this regimen. Patients receiving 5-FU/LV, capecitabine, or UFT/LV had older age, worse PS and lower disease stage (stage II) than patients receiving FOLFOX or CAPOX.
\end{abstract}

Key words: Adjuvant chemotherapy; Colon cancer; Capecitabine; 5-fluorouracil; Oxaliplatin 


\section{Introduction}

Colorectal cancer (CRC) is one of the most common malignancies, accounting for about $1,360,000$ new cases worldwide every year [1], and its incidence has increased sharply over the past two decades [2]. In South Korea, CRC is the second most common malignancy and the fourth most common cause of cancer-related deaths $[3,4]$.

Patients with stage I-III disease are candidates for curative resection, and selective patients with stage IV disease may also benefit from surgery. The majority of patients with stage I or II disease can be cured by curative surgery alone. However, more than half the patients with stage III disease who received curative resection eventually develop metastases during the course of their disease $[5,6]$. This may be explained by micrometastases of cancer cells before or at the time of surgery [7]. For such patients, adjuvant chemotherapy has a role to eradicate micrometastases and then prevent tumor recurrence [8]. Adjuvant chemotherapy is not recommended for most patients with stage II CRC. However, patients with high-risk factors, such as poorly differentiated histology, T4 lesions, inadequately sampled lymph nodes, or bowel perforation, could benefit from adjuvant treatment [8]. The benefits of adjuvant chemotherapy in terms of reducing recurrence and achieving superior disease-free survival (DFS) and overall survival (OS) in patients with resected colon cancer are well established [6, 9-13].

Until 2004, postoperative chemotherapy with 5 -fluorouracil and leucovorin (5-FU/LV) was the standard regimen for stage III colon cancer, based on a $24 \%$ relative reduction in mortality compared with surgery alone [6]. However, capecitabine, an oral fluoropyrimidine, can also be an effective alternative to 5-FU/LV as adjuvant treatment. In a randomized phase III study of capecitabine versus bolus 5-FU/LV (Mayo Clinic regimen), capecitabine showed an equivalent DFS to 5-FU/LV and was associated with significantly fewer toxicity profile [9]. In 2004, the Multicenter International Study of Oxaliplatin/5-Fluorouracil/Leucovorin in the Adjuvant Treatment of Colon Cancer (MOSAIC) trial reported that the addition of oxaliplatin to 5-FU/LV (FOLFOX) improved both DFS and OS in patients with stage III colon cancer [11].

Currently, the NCCN guidelines (http://www. nccn.org/patients/guidelines/colon/index.html\#4) recommend the use of 5-FU/LV, FOLFOX, capecitabine with oxaliplatin (CAPOX), or capecitabine as adjuvant chemotherapy for patients with high risk stage II and stage III colon cancer. In South Korea, various regimens including FOLFOX, CAPOX, 5-FU/LV, capecitabine, and oral uracil-tegafur/LV
(UFT/LV) can be used in the adjuvant setting under the coverage of public health insurance policy. However, the prescribing pattern and clinical factors that affect the selection of chemotherapeutic regimen have not been investigated. This study was conducted to investigate the actual practice in the use of adjuvant chemotherapy for patients with high-risk stage II or stage III colon cancer in South Korea.

\section{Patients and methods}

\section{Study design}

This study was a multi-center, open-labeled, prospective, observational study. The aim of the study was to evaluate the actual practice in adjuvant chemotherapy given to patients with colon cancer who underwent curative surgical resection. When assuming that the number of patients receiving an uncommonly used regimen would follow a Poisson distribution and patients have the odds of $90 \%$ of receiving an regimen that would be chosen with the $1 \%$ possibility, 230 patients were needed. Considering a drop-out rate of $10 \%$, a total of 253 patients were required for the study. The study duration was approximately 24 months, consisting of 18 months for registration and 6 months for follow-up.

This study was approved by the Institutional Review Boards of each participating institute. All patients provided written informed consent prior to the study entry. The study was conducted in accordance with the Declaration of Helsinki and Korean Ethical Guidelines for Clinical Research.

\section{Patients}

Patients receiving adjuvant chemotherapy after curative surgery for high-risk stage II or stage III colon cancer were eligible for the study. Stage II colon cancer with poorly differentiated histology, T4, inadequately sampled lymph nodes, or bowel perforation was considered high-risk disease. Patients with metastases completely resected, although their disease was stage IV, were also eligible. The other inclusion criteria were as follows: age over 18 years, Eastern Cooperative Oncology Group (ECOG) performance status (PS) of 2 or less, adequate bone marrow function (absolute neutrophil count $\geq 1.5 \times 10^{9} / \mathrm{L}$, platelet $\geq 100 \times 10^{9} / \mathrm{L}$, and hemoglobin $\geq 10 \mathrm{~g} / \mathrm{dL}$ ), adequate renal and hepatic function (serum creatinine $\leq 1.25 \mathrm{x}$ upper normal limit, hepatic enzymes and bilirubin $\leq$ $1.25 \mathrm{x}$ upper normal limit, prothrombin time $\leq 1.5 \mathrm{x}$ control). Patients with active infection or a history of cancer other than colon cancer and those participating in other clinical trials were excluded.

\section{Adjuvant chemotherapy}

At the time of starting this study, there were five 
different chemotherapy regimens usually prescribed to patients with colon cancer under the public health insurance policy; FOLFOX, CAPOX, 5-FU/LV, capecitabine, and UFT/LV. The usual dose and schedule of each regimen were presented in Table 1. Investigators were fully responsible for selecting chemotherapeutic regimen without any restriction.

\section{Data collection}

Data were collected from patients at three visits; visit 1 (registration day), visit 2 (3 months \pm 2 weeks), and visit 3 (6 months \pm 2 weeks). At visit 1 , patient's demographic information, diagnostic and clinical data of the disease, previous anti-cancer treatment, and the selected chemotherapy regimen were recorded. We also surveyed the reason why investigators chose the regimen. The reasons for selection of a certain regimen by an investigator were based on five categories: efficacy, safety, patient's age, co-morbidity, and disease stage. At visit 2 and 3, data on the progress or completion of the scheduled adjuvant chemotherapy were collected. If there were any changes in the dose of drugs and time interval, their reasons were recorded.

\section{Statistical analysis}

All statistical analyses were conducted using SAS software (version 9.2, SAS Institute, Cary, NC, USA). The categorical variables were presented with frequency and percentages. For the continuous variables, descriptive statistics such as mean, standard deviation, and median were calculated. Chi-square testing (or Fisher's exact testing) or Mann-Whitney U test was used to compare the demographic or clinical characteristics of the patients according to chemotherapeutic regimens. All $p$ values were based on a two-sided hypothesis, with a value of less than 0.05 being considered significant.

\section{Results}

\section{Patient baseline characteristics}

Ten surgical and two medical oncologists from 12 medical centers in South Korea participated in the study. Between December 2011 and December 2013, 249 patients were enrolled for the study. Excluding 3 patients who did not meet the eligibility criteria, 246 were analyzed. A total of 200 patients $(81.3 \%)$ completed the planned follow-up while $46(18.7 \%)$ discontinued the treatment early (Figure 1). Patients' demographics, tumor characteristics, and surgical method used for resecting tumor are presented in Table 2. The patients consisted of 142 male (57.8\%) and 104 female, with a median age of 63 years (range, 27-84 years). Almost all patients (97.6\%) showed good PS (ECOG 0 or 1). The most common tumor site was the sigmoid colon $(60.2 \%)$, followed by the ascending colon $(25.2 \%)$. More than half $(56.9 \%)$ patients received laparoscopic surgery and the remaining patients underwent tumor resection via laparotomy. In the majority of the patients $(80.1 \%)$, the tumors were moderately differentiated. About two-thirds of patients $(68.7 \%)$ had stage III disease and $5(2.0 \%)$ had stage IV. The median interval from surgery to adjuvant chemotherapy was 34 days (range, 21 to 141 days).

Table 1. The usual dose and schedule of chemotherapy regimens

\begin{tabular}{|c|c|c|}
\hline Regimen & Dose and route & Interval and duration \\
\hline FOLFOX & $\begin{array}{l}\text { Oxaliplatin }\left(85 \mathrm{mg} / \mathrm{m}^{2} \text { i.v. injection of over } 2 \mathrm{~h} \text { on day } 1\right) \text {, leucovorin }\left(200 \mathrm{mg} / \mathrm{m}^{2} \text { i.v. injection of over } 2 \mathrm{~h} \text { on day } 1\right. \\
\left.\text { and 2), and } 5 \text {-FU ( } 400 \mathrm{mg} / \mathrm{m}^{2} \text { i.v bolus injection, followed by } 600 \mathrm{mg} / \mathrm{m}^{2} \text { continuous i.v. injection on day } 1 \text { and } 2\right) \\
\text { [FOLFOX-4], or } \\
\text { Oxaliplatin }\left(85 \mathrm{mg} / \mathrm{m}^{2} \text { i.v. injection of over } 2 \mathrm{~h} \text { on day } 1\right) \text {, leucovorin }\left(400 \mathrm{mg} / \mathrm{m}^{2} \text { i.v. injection of over } 2 \mathrm{~h} \text { on day }\right. \\
\text { 1), and 5-FU ( } 400 \mathrm{mg} / \mathrm{m}^{2} \text { i.v. bolus injection on day 1, followed by } 2400 \mathrm{mg} / \mathrm{m}^{2} \text { continuous i.v. injection over } 46 \\
\text { hr) [mFOLFOX-6]. }\end{array}$ & Every 2 weeks for 12 cycles \\
\hline CAPOX & $\begin{array}{l}\text { Capecitabine }\left(1000 \mathrm{mg} / \mathrm{m}^{2} \text { orally administered twice a day for } 2 \text { weeks, followed by a one-week rest) and oxali- }\right. \\
\text { platin }\left(130 \mathrm{mg} / \mathrm{m}^{2} \text { i.v. injection over } 2 \mathrm{~h} \text { on day } 1\right) \text {. }\end{array}$ & Every 3 weeks for 8 cycles \\
\hline $5-\mathrm{FU} / \mathrm{LV}$ & $\begin{array}{l}\text { 5-FU }\left(425 \mathrm{mg} / \mathrm{m}^{2} \text { intravenous injection for } 5 \text { days }\right) \text { and leucovorin }\left(20 \text { or } 200 \mathrm{mg} / \mathrm{m}^{2} \text { i.v. injection for } 5 \text { days }\right) \text { [FL], } \\
\text { or } \\
\text { Leucovorin }\left(400 \mathrm{mg} / \mathrm{m}^{2} \text { i.v. injection over } 2 \mathrm{hr}\right) \text { and } 5-\mathrm{FU}\left(400 \mathrm{mg} / \mathrm{m}^{2} \text { i.v. bolus injection on day } 1 \text {, followed by }\right. \\
\left.2400 \mathrm{mg} / \mathrm{m}^{2} \text { continuous i.v. injection over } 46 \mathrm{hr}\right) \text { [LV5FU2] }\end{array}$ & $\begin{array}{l}\text { Every } 4 \text { weeks for } 6 \text { cycles } \\
\text { Every } 2 \text { weeks for } 12 \text { cycles }\end{array}$ \\
\hline Capecitabine & $1250 \mathrm{mg} / \mathrm{m}^{2}$ orally administered twice a day for 2 weeks, followed by a one-week rest. & Every 3 weeks for 8 cycles \\
\hline $\mathrm{UFT} / \mathrm{LV}$ & $\begin{array}{l}\text { Uracil-tegafur ( } 100 \mathrm{mg} / \mathrm{m}^{2} \text { orally administered three times a day) with or without leucovorin ( } 30 \mathrm{mg} \text { orally ad- } \\
\text { ministered three times a day on days } 1-28 \text {, followed by a one-week break). }\end{array}$ & Every 5 weeks for 5 cycles \\
\hline
\end{tabular}




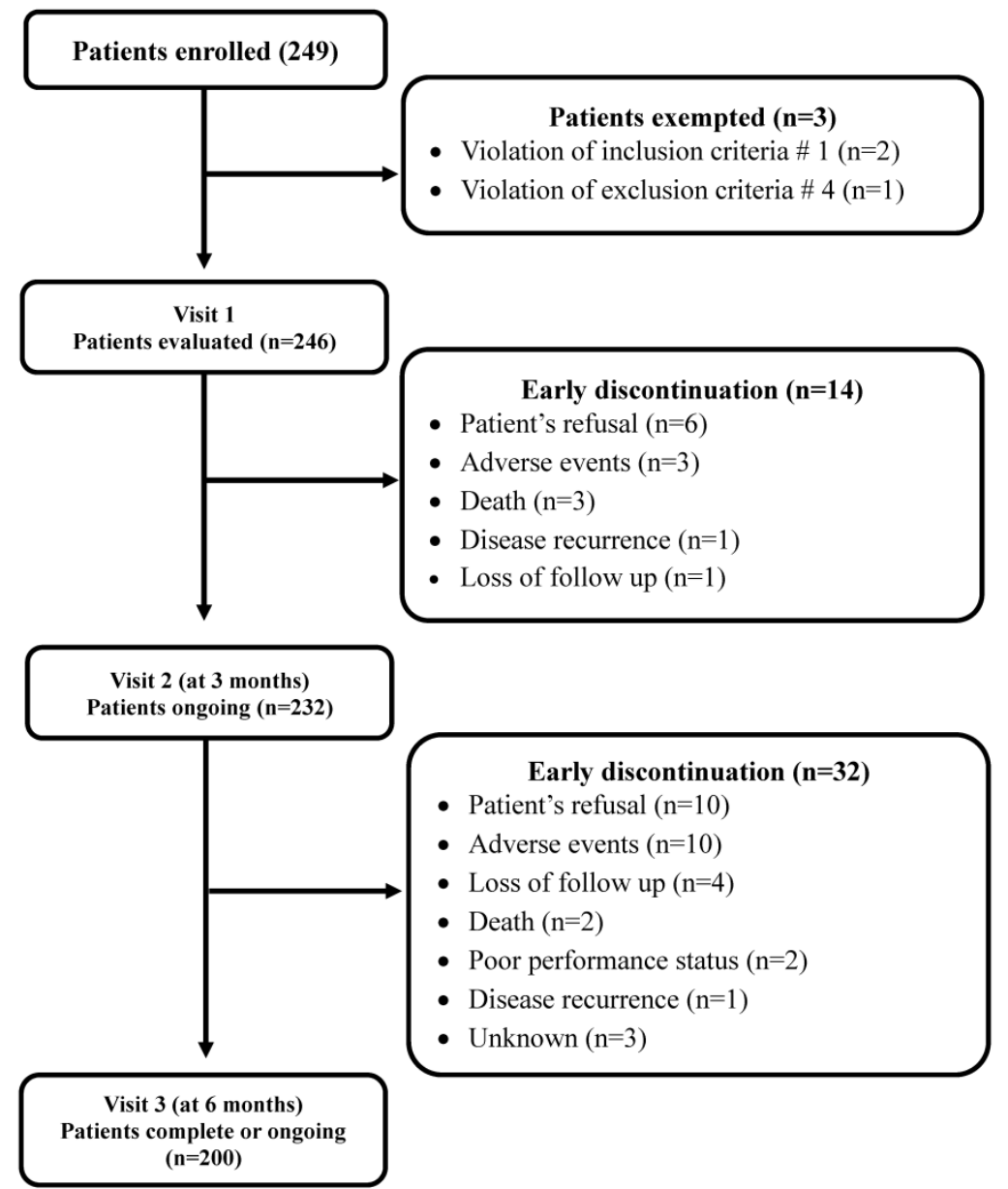

Figure 1. CONSORT diagram

Table 2. Demographics and clinical characteristics of the patients $(n=246)$

\begin{tabular}{|c|c|c|}
\hline Factors & & No. (\%) \\
\hline \multirow{2}{*}{ Gender } & Male & $142(57.7)$ \\
\hline & Female & $104(42.3)$ \\
\hline \multirow[t]{2}{*}{ Age (years) } & Median & 63 \\
\hline & Range & $27 \sim 84$ \\
\hline \multirow[t]{3}{*}{ ECOG PS ${ }^{*}$} & 0 & $133(54.1)$ \\
\hline & 1 & $107(43.5)$ \\
\hline & 2 & $6(2.4)$ \\
\hline \multirow[t]{2}{*}{ Surgical method } & Laparotomy & $106(43.1)$ \\
\hline & Laparoscopic resection & $140(56.9)$ \\
\hline \multirow[t]{5}{*}{ Tumor sites $\uparrow$} & Ascending colon & $62(25.2)$ \\
\hline & Transverse colon & $10(4.1)$ \\
\hline & Descending colon & $27(11.0)$ \\
\hline & Sigmoid colon & $148(60.2)$ \\
\hline & Appendix & $2(0.8)$ \\
\hline \multirow[t]{3}{*}{ Pathologic stage } & II & $72(29.3)$ \\
\hline & III & $169(68.7)$ \\
\hline & IV & $5(2.0)$ \\
\hline \multirow[t]{4}{*}{ Differentiation } & Well & $24(9.7)$ \\
\hline & Moderate & $197(80.1)$ \\
\hline & Poor & $14(5.7)$ \\
\hline & Unknown & $11(4.5)$ \\
\hline
\end{tabular}

* ECOG PS: Eastern Cooperative Group Performance Status

$\uparrow$ Overlapping data

\section{The selection of adjuvant chemotherapy regimens}

Out of 5 available regimens (FOLFOX, CAPOX, 5-FU/LV, capecitabine, and UFT/LV), FOLFOX was selected most commonly. Of 246 patients, 203 (82.5\%) received FOLFOX (FOLFOX-4 in 153 and modified FOLFOX-6 in 37) and 10 CAPOX. The remaining 33 patients received adjuvant chemotherapy with capecitabine (15), 5-FU/LV (12), or UFT/LV (6).

In terms of reasons for selecting specific regimens, investigators indicated the "efficacy" as the most important factor for FOLFOX (80.3\%) or CAPOX (100\%). For 5-FU/LV (58.3\%), capecitabine (40\%), and UFT/LV (66.7\%), the "safety" or "patient's characteristics (age, comorbidity, and stage)" was one of the most important selecting factors (Table 3 ).

\section{Demographic and clinical factors on the selec- tion of chemotherapy regimen}

When we compared clinical factors between combination therapy (FOLFOX or CAPOX) and monotherapy (5-FU/LV, capecitabine, or UFT/LV), patients receiving monotherapy had older age $(\mathrm{P}=$ 
0.0469), worse PS (ECOG 2) $(\mathrm{P}=0.0034)$, and lower disease stage (stage II) $(\mathrm{P}<0.001)$ than patients receiving combination therapy (Table 4).

\section{Clinical course of adjuvant chemotherapy}

At visit 2, dose adjustments and treatment delays occurred in $19.9 \%$ (49/246) and $29.7 \%$ (74/246), respectively. Dose adjustments were needed most commonly in patients receiving FOLFOX (21.2\%) or CAPOX (30.0\%). Patients receiving FOLFOX also most commonly experienced treatment delay $(32.5 \%)$. Three patients $(20 \%)$ with capecitabine experienced both dose adjustment and treatment delay (Table 5). Fourteen patients $(5.7 \%)$ discontinued the therapy early before visit 2 ( 3 months \pm 2 weeks); patient's refusal in 6 , adverse events in 3 , death in 3 , loss of follow-up in 1, and disease recurrence in 1 (Figure 1).

Out of 232 patients, additional $32(13.8 \%)$ discontinued the therapy before visit 3 (6 months \pm 2 weeks): patient's refusal in 10, adverse events in 10, loss of follow-up in 4, death in 2, poor PS in 2, and disease recurrence in 1 (Figure 1). From visit 2 to visit
3 , dose adjustments and treatment delays occurred in $18.5 \%$ (43/232) and 31.5\% (73/232), respectively. Similar to visit 2, patients on FOLFOX $(33.2 \%)$ or CAPOX $(33.3 \%)$ most commonly experienced treatment delay. Dose adjustment was needed in $20 \%(38 / 190)$ of patients on FOLFOX and in $26.7 \%(4 / 15)$ of those receiving capecitabine (Table 5).

Table 3. Reasons for selecting individual regimen

\begin{tabular}{|c|c|c|c|c|c|}
\hline Reason & $\begin{array}{l}\text { FOLFOX } \\
(n=203)\end{array}$ & $\begin{array}{l}\text { CAPOX } \\
(n=10)\end{array}$ & $\begin{array}{l}5-\mathrm{FU} / \mathrm{LV} \\
(\mathrm{n}=12)\end{array}$ & $\begin{array}{l}\text { Capecitabine } \\
(\mathrm{n}=15)\end{array}$ & $\begin{array}{l}\text { UFT/LV } \\
(n=6)\end{array}$ \\
\hline & No. (\%) & No. (\%) & No. (\%) & No. (\%) & No. (\%) \\
\hline Efficacy & $163(80.3)$ & $10(100)$ & $2(16.7)$ & $10(66.7)$ & $2(33.3)$ \\
\hline Safety & 39 (19.2) & $2(20)$ & $4(33.3)$ & $12(80)$ & $2(33.3)$ \\
\hline $\begin{array}{l}\text { Patient charac- } \\
\text { teristics }\end{array}$ & $61(30.1)$ & $4(40)$ & $7(58.3)$ & $6(40)$ & $4(66.7)$ \\
\hline Age & $6(3.0)$ & $1(10)$ & $2(16.7)$ & $6(40)$ & $4(66.7)$ \\
\hline Co-morbidity & $1(0.5)$ & 0 & $1(8.3)$ & $1(6.7)$ & 0 \\
\hline Stage & $60(29.6)$ & $4(40)$ & $5(41.7)$ & $1(6.7)$ & 0 \\
\hline
\end{tabular}

Data overlapping was allowed.

FOLFOX: leucovorin, 5-fluorouracil, and oxaliplatin; CAPOX: capecitabine and oxaliplatin; 5-FU/LV: 5-fluorouracil with leucovorin; UFT/LV: uracil-tegafur and leucovorin

Table 4. Comparison of demographic and clinical characteristics according to therapy

\begin{tabular}{|c|c|c|c|c|}
\hline & & Monotherapy $(\mathrm{n}=33)$ No. $(\%)$ & Combination therapy $(n=213)$ No. $(\%)$ & p-value \\
\hline Division & Surgical oncologist Medical oncologist & $27(13.1) 6(15.0)$ & $179(86.9) 34(85.0)$ & $0.7478 \dagger$ \\
\hline Age & Median (range) & $71(30-84)$ & $62(27-80)$ & $0.0469 \ddagger$ \\
\hline ECOG & 0,12 & $29(12.1) 4(66.7)$ & $211(87.9) 2(33.3)$ & $0.0034^{\wedge}$ \\
\hline Gender & Male Female & 18 (12.7) 15 (14.4) & $124(87.3) 89(85.6)$ & $0.6912 \dagger$ \\
\hline Stage & II III IV & $20(27.8) 12(7.1) 1(20.0)$ & 52 (72.2) 157 (92.9) 4 (80.0) & $<0.001^{\wedge}$ \\
\hline Differentiation & $\begin{array}{l}\text { Well } \\
\text { Moderate } \\
\text { Poor } \\
\text { Unknown }\end{array}$ & $\begin{array}{l}2(8.3) \\
27(13.7) \\
2(14.3) \\
2(18.2)\end{array}$ & $\begin{array}{l}22(91.7) \\
170(86.3) \\
12(85.7) \\
9(81.8)\end{array}$ & $0.8225^{\wedge}$ \\
\hline Operation & $\begin{array}{l}\text { Laparotomy } \\
\text { Laparoscope }\end{array}$ & $\begin{array}{l}14(13.2) \\
19(13.6)\end{array}$ & $\begin{array}{l}92(86.8) \\
121(86.4)\end{array}$ & $0.9339 \dagger$ \\
\hline $\begin{array}{l}\text { Preoperative CEA } \\
(\mathrm{ng} / \mathrm{mL})^{\#}\end{array}$ & Median (range) & $4.2(0.94-50.2)$ & $3.4(0.2-260.8)$ & $0.3455 \ddagger$ \\
\hline
\end{tabular}

Table 5. Clinical course of adjuvant chemotherapy

\begin{tabular}{|c|c|c|c|c|c|c|c|}
\hline & & $\begin{array}{l}\text { FOLFOX } \\
(\mathrm{n}=203)\end{array}$ & $\begin{array}{l}\text { CAPOX } \\
(n=10)\end{array}$ & $\begin{array}{l}5-\mathrm{FU} / \mathrm{LV} \\
(\mathrm{n}=12)\end{array}$ & $\begin{array}{l}\text { Capecitabine } \\
(\mathrm{n}=15)\end{array}$ & $\begin{array}{l}\text { UFT/LV } \\
(\mathrm{n}=6)\end{array}$ & $\begin{array}{l}\text { Total } \\
(\mathrm{n}=246)\end{array}$ \\
\hline \multirow[t]{3}{*}{ Visit 2} & Dose adjustment & $43(21.2)$ & $3(30)$ & 0 & $3(20)$ & 0 & $49(19.9)$ \\
\hline & Treatment delay & $66(32.5)$ & $2(20)$ & $1(8.3)$ & $3(20)$ & $1(16.7)$ & $73(29.7)$ \\
\hline & Early stop & $13(6.4)$ & $1(10)$ & 0 & 0 & 0 & $14(5.7)$ \\
\hline \multicolumn{2}{|c|}{ No. of patients ongoing } & 190 & 9 & 12 & 15 & 6 & 232 \\
\hline \multirow{3}{*}{ Visit 3} & Dose adjustment & $38(20)$ & $1(11.1)$ & 0 & $4(26.7)$ & 0 & $43(18.5)$ \\
\hline & Treatment delay & $63(33.2)$ & $3(33.3)$ & $3(25.3)$ & $3(20)$ & $1(16.7)$ & $73(31.5)$ \\
\hline & Early stop & $29(15.3)$ & 0 & $1(8.3)$ & $2(13.3)$ & 0 & $32(13.8)$ \\
\hline \multicolumn{2}{|c|}{ No. of patients completed } & 161 & 9 & 11 & 13 & 6 & 200 \\
\hline
\end{tabular}

Data overlapping was allowed.

FOLFOX: leucovorin, 5-fluorouracil, and oxaliplatin; CAPOX: capecitabine and oxaliplatin; 5-FU/LV: 5-fluorouracil with leucovorin; UFT/LV: uracil-tegafur and leucovorin 
In total, 82 patients $(33.3 \%)$ received dose adjustment and 112 (45.5\%) experienced treatment delay during the study period. At both visit 2 and visit 3, hematologic toxicities $(59.7 \%$ and $58.2 \%$, respectively, data no shown) were the most common cause of dose adjustment. Although hematologic toxicities was also the most common cause of treatment delay $(53.5 \%$ and $49.6 \%$, respectively), about $30 \%$ of patients postponed treatment because of personal reasons (data no shown).

At the time of visit 3, 174 patients $(70.7 \%)$ completed adjuvant chemotherapy and $26(10.6 \%)$ were still receiving the treatment. The remaining 46 patients $(18.7 \%)$ discontinued early adjuvant treatment because of various causes: patient's refusal in 16, adverse events in 13 , loss of follow-up in 5 , disease recurrence in 2, poor PS in 2, death in 5 (disease progression in 2, adverse events in 3), and unknown in 3.

\section{Discussion}

This was the first observational study to investigate the prescribing pattern of adjuvant chemotherapy for patients with colon cancer in South Korea. Of five adjuvant chemotherapy regimens being prescribed in clinical practice, FOLFOX was the most commonly used regimen $(82.5 \%)$, followed by capecitabine $(6.1 \%)$. The "efficacy" was the major reason for the selection of combination chemotherapy (FOLFOX or CAPOX), and the "safety" or "patient's characteristics (age, comorbidity, and stage)" was one of the most important selecting factors for monotherapy (5-FU/LV, capecitabine, or UFT/LV). Hematologic toxicities were the most common cause of dose adjustment and treatment delay.

Since the MOSAIC study in 2004 [11], the addition of oxaliplatin to fluorouracil-based adjuvant chemotherapy was considered the standard treatment for high-risk stage II and stage III colon cancer $[12,13]$. In the MOSAIC study, FOLFOX regimen was associated with 3-year DFS rate of $78.2 \%$ as compared to $72.9 \%$ observed with $5-\mathrm{FU} / \mathrm{LV}$ regimen $(\mathrm{P}=0.002)$ in patients with stage II and stage III colon cancer [11]. The combination of oxaliplatin and 5-FU/LV also significantly improved 6 -year survival rate $(78.5 \%$ vs. $76.0 \% \mathrm{P}=0.046)$ [13]. As compared to $5-\mathrm{FU} / \mathrm{LV}$, the addition of oxaliplatin to capecitabine (CAPOX) improved DFS in patients with stage III colon cancer [14]. In the current study, FOLFOX and CAPOX were selected in $86.6 \%(213 / 246)$ of the patients. Our investigators indicated the "efficacy" as the most important reason for selecting these regimens. These results are in concordance with those of the population-based cohort study conducted by Abrams et al. in patients with stage II or III colon cancer in the U.S [15]. The addition of oxaliplatin to fluorouracil-based adjuvant chemotherapy sharply increased after 2004 and represented $90 \%$ of adjuvant chemotherapy in stage III disease by 2007. In spite of convenience and comparable efficacy of CAPOX [14], however, FOLFOX that usually requires hospitalization for 3 or 4 days was predominantly selected as adjuvant chemotherapeutic regimen in our study. This finding may reflect that patients prefer to be hospitalized for chemotherapy because of health insurance benefits in South Korea.

In our study, monotherapy (5-FU/LV, capecitabine, or UFT/LV) was prescribed in $13.4 \%(33 / 246)$ of patients. Patients receiving monotherapy had older age, worse PS (ECOG 2), and lower stage (stage II) than patients receiving combination therapy (FOLFOX or CAPOX). These findings are also in concordance with those of the study by Abrams et al. in which increasing age and diminishing PS were inversely associated with the addition of oxaliplatin to adjuvant chemotherapy regimens. In our study, investigators indicated the "safety" or "patients characteristics (age, comorbidity, and stage)" as one of the most important factors for monotherapy. In a pooled analysis, 5-FU-based adjuvant chemotherapy (5-FU/LV or 5-FU plus levamisole) showed an improved recurrence-free survival [hazard ratio $(\mathrm{HR})=$ $0.68]$ and $\mathrm{OS}(\mathrm{HR}=0.76)$, compared to surgery-alone [6]. Capecitabine has also shown an equivalent DFS to 5-FU/LV and has been associated with significantly tolerable toxicity profile [9]. Adjuvant UFT/LV was non-inferior to 5-FU/LV with respect to DFS in a randomized phase III trial of adjuvant chemotherapy in patients with stage III colorectal cancer (JCOG0205) [16]. In the adjuvant setting, the benefit of adding oxaliplatin to fluoropyrimidine (FOLFOX or CAPOX) for elderly patients is controversial [17-20]. In a retrospective study, oxaliplatin-containing regimens showed only a small survival benefit over non-oxaliplatin regimens for elderly patients (75 years or older) with stage III colon cancer [17]. A pooled analysis of adjuvant trials containing oxaliplatin showed no significant benefit in terms of DFS or OS, compared to 5-FU/LV in patients older than 70 years [18]. The subgroup analysis of the NSABP C-07 trial found that the addition of oxaliplatin to 5-FU/LV achieved no survival benefit in patients older than 70 years with stage II or III colon cancer, with a trend of decreased survival $(H R=1.18)$ [19]. In the subset analysis of the MOSAIC trial [11], older patients (aged 70 to 75 years) with stage II or III colon cancer showed no survival benefit from the addition of oxaliplatin [20]. Therefore, 5-FU/LV, capecitabine, or UFT/LV may be a reasonable option for patients with old age or poor PS [21].

During the study period, $33.3 \%$ of the patients received dose adjustment and $45.5 \%$ experienced treatment delay. As expected, hematologic toxicities 
were the most common cause of dose adjustment at both visit 2 and visit 3 . Although hematologic toxicities were also the most common cause of treatment delay, about $30 \%$ of patients postponed treatment because of personal reasons. Despite recommendation of adjuvant chemotherapy for 6 months, about $6 \%$ of patients discontinued the treatment before visit 2 (3 months \pm 2 weeks). This proportion is much lower than that of the study by Abrams et al. in which $30 \%$ of patients discontinued all adjuvant therapy after less than 3 months [14]. The differences in the time and design between the two studies may partly explain this finding: the study by Abrams et al was a population-based cohort survey conducted between 2004 and 1010, while ours was well controlled observational study conducted recently. In both studies, however, patients with old age, poor PS, and oxaliplatin-containing regimens (FOLFOX or CAPOX) appeared to be more likely to stop early adjuvant treatment. In our study, $70.7 \%$ of patients finished adjuvant chemotherapy within 6 months.

In our study, no patients received monoclonal antibodies. Target agents such as cetuximab or bevacizumab have broadened treatment options for patients with metastatic colorectal cancer. In the adjuvant setting, however, cetuximab or bevacizumab did not prolong DFS when added to adjuvant chemotherapy for patients with resected stage III colon cancer $[22,23]$. As of now, there is no indication of targeted agents in the adjuvant setting of colon cancer.

Of note, this study has a major limitation. Most investigators in our study were surgical oncologists except for two medical oncologists. In many medical centers of South Korea, surgical oncologists refer their patients to medical oncologists. Therefore, our observation may show primarily the trend of surgical oncologists. Considering that investigators most commonly chose FOLFOX because of the efficacy, however, the results appear to reflect the actual practice of adjuvant chemotherapy in patients with colon cancer.

In conclusion, FOLFOX was the most commonly used chemotherapeutic regimen and its efficacy was the main reason for selecting this regimen in South Korea. Patients receiving 5-FU/LV, capecitabine, or UFT/LV had older age, worse PS and lower disease stage than patients receiving FOLFOX or CAPOX. Hematologic toxicities were the most common cause of dose adjustment and treatment delay.

\section{Acknowledgements}

The authors would like to thank Anahita Gouri, Dr. Alina Gomes (Sanofi, Mumbai), and Vimal Kumar Varma (Jeevan Scientific Technology Limited, Hy- derabad, India) for helping us to prepare this manuscript.

\section{Funding}

This work was supported by sanofi-aventis Korea.

\section{Conflict of interest}

There are no conflicts of interest to report.

\section{References}

1. Ferlay J, Soerjomataram I, Dikshit R, Eser S, Mathers C, Rebelo M, et al. Cancer incidence and mortality worldwide: Sources, methods and major patterns in GLOBOCAN 2012. Int J Cancer. 2015;136:E359-86.

2. Shin A, Kim KZ, Jung KW, Park S, Won YJ, Kim J, et al. Increasing Trend of Colorectal Cancer Incidence in Korea, 1999-2009. Cancer Res Treat. 2012;44:219-26.

3. Jung KW, Won YJ, Kong HJ, Oh CM, Lee DH, Lee JS. Prediction of cancer incidence and mortality in Korea, 2014. Cancer Res Treat. 2014:46:124-30.

4. Jung KW, Won YJ, Kong HJ, Oh CM, Cho H, Lee DH, Lee KH. Cancer Statistics in Korea: Incidence, Mortality, Survival, and Prevalence in 2012. Cancer Res Treat. 2015;47:127-41.

5. Choi DR, Yoon SN, Kim HS, Kim JH, Kim KY, Kim BC, et al. A phase II study of capecitabine and oral leucovorin as a third-line chemotherapy in patients with metastatic colorectal cancer. Cancer Chemother Pharmacol. 2015;75:639-43.

6. Gill S, Loprinzi CL, Sargent DJ, Thomé SD, Alberts SR, Haller DG, et al. Pooled analysis of fluorouracil-based adjuvant therapy for stage II and III colon cancer: who benefits and by how much? J Clin Oncol. 2004;22:1797-806.

7. Feezor RJ, Copeland EM 3rd, Hochwald SN. Significance of micrometastases in colorectal cancer. Ann Surg Oncol. 2002;9:944-53.

8. Chau I, Cunningham D. Adjuvant therapy in colon cancer-what, when and how? Ann Oncol. 2006;17:1347-59.

9. Twelves C, Wong A, Nowacki MP, Abt M, Burris H 3rd, Carrato A, et al. Capecitabine as adjuvant treatment for stage III colon cancer. N Engl J Med. 2005;352:2696-704

10. Arkenau HT, Bermann A, Rettig K, Strohmeyer G, Porschen R; Arbeitsgemeinschaft Gastrointestinale Onkologie. 5-Fluorouracil plus leucovorin is an effective adjuvant chemotherapy in curatively resected stage III colon cancer: long-term follow-up results of the adjCCA-01 trial. Ann Oncol. 2003;14:395-9.

11. André T, Boni C, Mounedji-Boudiaf L, Navarro M, Tabernero J, Hickish T, et al. Multicenter International Study of Oxaliplatin/5-Fluorouracil/Leucovorin in the Adjuvant Treatment of Colon Cancer (MOSAIC) Investigators. Oxaliplatin, fluorouracil, and leucovorin as adjuvant treatment for colon cancer. $\mathrm{N}$ Engl J Med. 2004;350:2343-51.

12. Kuebler JP, Wieand HS, O'Connell MJ, Smith RE, Colangelo LH, Yothers G, et al. Oxaliplatin combined with weekly bolus fluorouracil and leucovorin as surgical adjuvant chemotherapy for stage II and III colon cancer: results from NSABP C-07. J Clin Oncol. 2007;25:2198-204.

13. Andre T, Boni C, Navarro M, Tabernero J, Hickish T, Topham C, et al. Improved overall survival with oxaliplatin, fluorouracil, and leucovorin as adjuvant treatment in stage II or III colon cancer in the MOSAIC trial. J Clin Oncol. 2009·27:3109-16.

14. Haller DG, Tabernero J, Maroun J, de Braud F, Price T, Van Cutsem E, et al. Capecitabine plus oxaliplatin compared with fluorouracil and folinic acid as adjuvant therapy for stage III colon cancer. J Clin Oncol. 2011;29:1465-71.

15. Abrams TA, Brightly R, Mao J, Kirkner G, Meyerhardt JA, Schrag D, Fuchs CS. Patterns of adjuvant chemotherapy use in a population-based cohort of patients with resected stage II or III colon cancer. J Clin Oncol. 2011;29:1200-10.

16. Shimada $Y$, Hamaguchi T, Mizusawa J, Saito N, Kanemitsu Y, Takiguchi N, et al. Randomised phase III trial of adjuvant chemotherapy with oral uracil and tegafur plus leucovorin versus intravenous fluorouracil and levofolinate in patients with stage III colorectal cancer who have undergone Japanese D2/D3 lymph node dissection: final results of JCOG0205. Eur J Cancer. 2014;50:2231-40.

17. Sanoff HK, Carpenter WR, Stürmer T, Goldberg RM, Martin CF, Fine JP, et al. Effect of adjuvant chemotherapy on survival of patients with stage III colon cancer diagnosed after age 75 years. J Clin Oncol. 2012;30:2624-34.

18. McCleary NJ, Meyerhardt JA, Green E, Yothers G, de Gramont A, Van Cutsem $E$, et al. Impact of age on the efficacy of newer adjuvant therapies in patients with stage II/III colon cancer: findings from the ACCENT database. J Clin Oncol. 2013;31:2600-6.

19. Yothers G, O'Connell MJ, Allegra CJ, Kuebler JP, Colangelo LH, Petrelli NJ, Wolmark N. Oxaliplatin as adjuvant therapy for colon cancer: updated results of NSABP C-07 trial, including survival and subset analyses. J Clin Oncol. 2011;29:3768-74

20. Tournigand $\mathrm{C}$, André $\mathrm{T}$, Bonnetain $\mathrm{F}$, Chibaudel B, Lledo $\mathrm{G}$, Hickish $\mathrm{T}$, et al. Adjuvant therapy with fluorouracil and oxaliplatin in stage II and elderly patients (between ages 70 and 75 years) with colon cancer: subgroup analyses of 
the Multicenter International Study of Oxaliplatin, Fluorouracil, and Leucovorin in the Adjuvant Treatment of Colon Cancer trial. J Clin Oncol. 2012;30:3353-60.

21. Kim JH. Chemotherapy for colorectal cancer in the elderly. World J Gastroenterol. 2015;21:5158-66.

22. Alberts SR, Sargent DJ, Nair S, Mahoney MR, Mooney M, Thibodeau SN, et al, Effect of oxaliplatin, fluorouracil, and leucovorin with or without cetuximab on survival among patients with resected stage III colon cancer: a randomized trial. JAMA. 2012;307:1383-93.

23. de Gramont A, Van Cutsem E, Schmoll HJ, Tabernero J, Clarke S, Moore MJ, et al. Bevacizumab plus oxaliplatin-based chemotherapy as adjuvant treatment for colon cancer (AVANT): a phase 3 randomised controlled trial. Lancet Oncol. 2012;13:1225-33. 